University of New Hampshire

University of New Hampshire Scholars' Repository

Natural Resources and the Environment

Scholarship

Natural Resources and the Environment

3-2013

\title{
Comparison of forest attributes derived from two terrestrial lidar systems.
}

\author{
Mark J. Ducey \\ University of New Hampshire, mark.ducey@unh.edu \\ Rasmus Astrup \\ Norwegian Forest and Landscape Institute \\ Stefan Seifart \\ Technische Universität München \\ Hans Pretzsch \\ Technische Universität München \\ Bruce C. Larson \\ University of Washington - Seattle Campus
}

See next page for additional authors

Follow this and additional works at: https://scholars.unh.edu/nren_facpub

Part of the Forest Sciences Commons

\section{Recommended Citation}

Ducey, M.J., Astrup, R., Seifert, S., Pretzsch, H., Larson, B.C., David Coates, K. Comparison of forest attributes derived from two terrestrial lidar systems. (2013) Photogrammetric Engineering and Remote Sensing, 79 (3), pp. 245-257. DOI:10.14358/PERS.79.3.245

This Article is brought to you for free and open access by the Natural Resources and the Environment at University of New Hampshire Scholars' Repository. It has been accepted for inclusion in Natural Resources and the Environment Scholarship by an authorized administrator of University of New Hampshire Scholars' Repository. For more information, please contact Scholarly.Communication@unh.edu. 


\section{Authors}

Mark J. Ducey, Rasmus Astrup, Stefan Seifart, Hans Pretzsch, Bruce C. Larson, and K David Coates 


\title{
Comparison of Forest Attributes Derived from Two Terrestrial Lidar Systems
}

\author{
Mark J. Ducey, Rasmus Astrup, Stefan Seifert, Hans Pretzsch, \\ Bruce C. Larson, and K. David Coates
}

\begin{abstract}
Terrestrial lidar (TLS) is an emerging technology for deriving forest attributes, including conventional inventory and canopy characterizations. However, little is known about the influence of scanner specifications on derived forest parameters. We compared two TLS systems at two sites in British Columbia. Common scanning benchmarks and identical algorithms were used to obtain estimates of tree diameter, position, and canopy characteristics. Visualization of range images and point clouds showed clear differences, even though both scanners were relatively high-resolution instruments. These translated into quantifiable differences in impulse penetration, characterization of stems and crowns far from the scan location, and gap fraction. Differences between scanners in estimates of effective plant area index were greater than differences between sites. Both scanners provided a detailed digital model of forest structure, and gross structural characterizations (including crown dimensions and position) were relatively robust; but comparison of canopy density metrics may require consideration of scanner attributes.
\end{abstract}

\section{Introduction}

In the past decade, terrestrial lidar systems (TLS) have shown promise as tools for estimating standard forest inventory variables (e.g., Aschoff et al., 2004; Henning and Radtke, 2006b; Maas et al., 2008; Thies and Spiecker, 2004; Watt and Donoghue, 2005), and forest canopy structure and attributes (e.g., Clawges et al., 2007; Henning and Radtke, 2006a; Hosoi and Omasa, 2009; Huang and Pretzsch, 2010; Moorthy et al., 2008; Vierling et al. 2008; Zheng and Moskal, 2009). For standard forest inventories, research efforts have focused

Mark J. Ducey is with the University of New Hampshire, Department of Natural Resources and the Environment, 114 James Hall, Durham, NH 03824, (mjducey@cisunix.unh. edu).

Rasmus Astrup is with Norsk Institutt for Skog og Landskap, Postboks 115, NO-1431 Ås, Norway.

Stefan Seifert and Hans Pretzsch are with Forest Growth and Yield Science, Technische Universität München, Hans-Carl-vonCarlowitz-Platz 2, DE-85354 Freising, Germany.

Bruce C. Larson is with the University of British Columbia, Forest Sciences Centre, 2424 Main Mall, Vancouver, BC V6T 1Z4, Canada.

K. David Coates is with the Ministry of Forests, Lands and Natural Resource Operations, Bag 6000, Smithers, British Columbia V0J N20 Canada, and Bulkley Valley Research Centre, Box 4274, Smithers, British Columbia V0J 2N0 Canada. on automatic detection of individual trees (e.g., Brolly and Kiraly, 2009; Maas et al., 2008; Simonse et al., 2003) and the subsequent estimation of parameters such as tree diameters and height (e.g., Aschoff and Spiecker, 2004; Henning and Radtke, 2006b; Hopkinson et al., 2004; Maas et al., 2008; Strahler et al., 2008) and taper or other stem quality attributes (Henning and Radtke, 2006b; Lefsky and McHale 2008; Thies et al., 2004). With regard to crown structure, research efforts have focused on measures such as gap fraction, plant area index, and leaf area index (LAI) at the plot level (Henning and Radtke, 2006a; Hosoi and Omasa, 2009; Strahler et al., 2008; Zheng and Moskal, 2009), or individual tree level (e.g., Clawges et al., 2007; Huang and Pretzsch, 2010; Moorthy et al., 2008), or branch and leaf level (e.g., Eitel et al., 2010; Hosoi et al., 2011). Dassot et al. (2011) provide a recent review of past research and potential applications.

The effect of scanner setup pattern (single scan mode versus multiple scan mode) (Maas et al., 2008; Van der Zande et al., 2008) and scanner position in the canopy (Hosoi and Omasa, 2007; Van der Zande et al., 2006) on the retrieved inventory and canopy structure parameters has received some attention in the literature. By contrast, the effect of the scanner systems themselves on derived forest attributes has received only minor attention. The only published comparison of scanner systems for forestry applications used different scanners on different plots, illustrating differences in performance but not allowing direct comparison (Maas et al., 2008). Today, a wide variety of commercial TLS systems exist, and the systems applied in forest-related applications range from 2D systems with low resolution (e.g., Rossel et al., 2009; Van der Zande et al., 2006) to 3D systems with much higher resolution (e.g., Eitel et al., 2010; Henning and Radtke, 2006a,b; Hosoi et al., 2011). From detailed studies of canopy structure with hemispherical photography, it is apparent that factors such as resolution may be important for the derived canopy parameters (Englund et al., 2000; Hale and Edwards, 2002; Jonckheere et al., 2004). Differences in pulse penetration have been demonstrated between TLS and airborne lidar (Chasmer et al., 2006; Hilker et al., 2010 and 2012). For TLS applications, it has been suggested that scanner system specifications might be important for derived forest attributes (Clawges et al., 2007; Zheng and Moskal, 2009), but the possible effects have not been formally investigated through field trials. Understanding the impact of scanner specifications on derived attributes is especially important for future deployment in successive surveys designed to estimate changes

Photogrammetric Engineering \& Remote Sensing Vol. 79, No. 3, March 2013, pp. 245-257.

0099-1112/13/7903-245/\$3.00/0 (C) 2013 American Society for Photogrammetry and Remote Sensing 
in crown and stem characteristics, as scanner technology is changing quite rapidly whereas forest growth is a relatively slow process.

The objective of our study was to investigate the effect of two TLS systems on selected forest inventory and canopy structure variables. We met our objective by (a) scanning two different forest stand types with two different TLS systems, (b) comparing the stem mapping and tree diameter distribution derived from the two systems, and (c) comparing the canopy attributes, derived gap fractions, and LAI from the two stands.

\section{Methods}

\section{Study Sites}

Field data for the study were collected in two forest stands (Table 1) around Smithers in northwestern British Columbia, Canada $\left(54^{\circ} 35^{\prime} \mathrm{N}, 126^{\circ} 55^{\prime} \mathrm{W}\right)$. The study area has a continental climate with cold temperatures and snowy winters and is part of the Sub-Boreal Spruce, moist cold subzone (SBSMc2; Banner et al., 1993; Meidinger and Pojar, 1991). Lodgepole pine (Pinus contorta var. latifolia Engelm.) dominated stands are most abundant on the poorer and drier soils while interior spruce (a complex of white spruce Picea glauca (Moench) Voss and Engelmann spruce (P. engelmannii Parry ex Engelm.)), and subalpine fir (Abies lasiocarpa (Hook.) Nutt.) normally dominate mature forests on moisture-receiving sites. Sites intermediate in soil moisture and nutrient availability often support mixed forests of all three conifer species.

We selected two mature forest stands as a study sites (Table 1) representing a contrast in terms of soil nutrient availability and associated species composition and density. Site 1 is a nutrient-poor site dominated by pine and with a relatively open canopy, and Site 2 is a nutrient-rich site dominated by subalpine fir and spruce with a denser, more verticallycomplex canopy. At both sites, trees were stem-mapped and measured for their diameter at breast height (DBH) in the immediate vicinity of the central scan point.

\section{Laser Scanning}

We used a Riegl LMS-Z360i and a Leica ScanStation to carry out scans at multiple positions on both study sites. The two scanners differ in key characteristics (Table 2), which potentially can affect the estimation of key canopy metrics. For each study site, one scan position was located in the plot center, and the remaining scan positions were located around it. The edge scan positions were located so that 10 to 20 trees were completely scanned from all sides and the crown shape and height of the trees immediately adjacent to the plot center could be seen from multiple scan points. Both scanners were deployed over identical scan points. However, due to differences in tripods and other aspects of scanner ergonomics, the

TABle 1. Study Site Characteristics

\begin{tabular}{lll}
\hline Site & Site 1 & Site 2 \\
\hline Site type & Nutrient poor & Nutrient rich \\
Basal area $\left(\mathrm{m}^{2} / \mathrm{ha}\right)$ & 42 & 59 \\
Stems/ha & 1517 & 1644 \\
$\begin{array}{l}\text { Species composition (pine, } \\
\text { spruce, fir) }\end{array}$ & $51 \%, 27 \%, 22 \%$ & $9 \%, 28 \%, 63 \%$ \\
$\begin{array}{l}\text { Age range (breast height) } \\
\text { (years) }\end{array}$ & $9-71$ & $92-182$ \\
Median age (years) & & \\
Top height & 57 & 150 \\
No. of scans & $25 \mathrm{~m}$ & $35 \mathrm{~m}$ \\
\hline
\end{tabular}

Table 2. Comparison of Key Scanner Specifications

\begin{tabular}{lll}
\hline Scanner & Riegl LMS-Z360i & Leica ScanStation \\
\hline Scanner type & Time of flight & Time of flight \\
Return & Last return/First return* & First return \\
Laser class & 1 & $3 \mathrm{R}$ \\
Color (wavelength) & $1550 \mathrm{~nm}$ & $532 \mathrm{~nm}$ \\
$\begin{array}{l}\text { Resolution (in this } \\
\text { study) }\end{array}$ & 0.12 degrees & 0.20 degrees \\
Beam divergence & $2 \mathrm{mrad}^{* *}$ & $0.2 \mathrm{mrad}$ \\
Beam footprint at $10 \mathrm{~m}$ & $20 \mathrm{~mm}^{*}$ & $6 \mathrm{~mm}$ \\
\hline
\end{tabular}

* Site 2 was scanned twice with the Riegl LMS-Z360i in order to obtain datasets with last and first return.

**The scanner incorporates an integrated beam focusing system. In our study this was set at infinity.

height above the scan point benchmarks differed between scanners.

In the case of the Riegl LMS-Z360i, the angular distance between two distance measurements was set to 0.12 degree, which corresponds to a point spacing of approximately $2 \mathrm{~cm}$ if the target is $10 \mathrm{~m}$ from the scanner. The Riegl LMS-Z360i scanner has a horizontal scan capability of 360 degrees and a vertical field of view of 85 degrees. To provide coverage of the total canopy, the scanner was tilted, and a second scan was made from each scan position to obtain the upper tree sections. Before scanning, retro-reflective targets were positioned around the scanning area. Each target was scanned with the highest resolution of the scanner from each scan position. As a postprocessing step, the co-registration of the scan points was made by automatically matching the centroids of the retro-reflective targets. The central scan was always oriented to magnetic north by using a compass. To obtain a vertically oriented local coordinate system, a bubble level was used to ensure that the scanner was positioned upright. At Site 1, the Riegl was used only in last return mode (i.e., the farthest return distance associated with an individual pulse was converted to an x, y, z coordinate); at Site 2, the Riegl was used in both first (i.e., nearest) and last return mode to compare performance.

In the case of the Leica ScanStation, the angular distance between the two distance measurements was set to 0.20 degree, which corresponds to a point spacing of approximately $3.5 \mathrm{~cm}$ if the target is $10 \mathrm{~m}$ from the scanner. The Leica has a horizontal scan capability of 360 degrees and a vertical field of view of 135 degrees (from 45 degrees below the horizontal, up to the zenith), and hence only one scan was needed at each scan point. Co-registration of scan points was achieved by conducting a closed traverse, using a circular target at the foresight and backsight position for each scan point, and using the built-in dual-axis tilt compensator of the scanner to ensure vertical accuracy.

\section{Analysis}

Postprocessing

To ensure differences in key results reflected scanner differences rather than postprocessing differences, we employed identical postprocessing procedures for both scanners, with each step performed by members of a single research team using data from both scanners, with the exception of coregistration of points within a site, which was done automatically within the Leica software. First, all data were exported to ASCII files. Next, all data for each scanner at each site were combined into single files that included the (x, y, z) coordinates of all contacts, the identity and location of the scanner 
position associated with the contacts, and coordinate information for each probe that did not return a contact. The files were translated into a common coordinate system for both scanners, and served as the basis for all further analyses.

\section{Visualization}

We used visual comparison of a series of images derived from scanner data as an initial basis for comparison to facilitate better understanding of the quantitative differences that might be uncovered later. Visualization is inherently subjective, but the ability of the human visual system to perceive patterns in optical data remains unsurpassed by quantitative and computational techniques, despite decades of research (Neumann et al., 2007; Todd, 2004). Visualization of scanner data thus represents an avenue toward understanding what quantitative algorithms might be able to do with such data, and discerning what patterns in the data might be important for current algorithms.

As a first step in scanner comparison, we created range images from the data from each scanner at each scanning position. Contacts occurring at a range of $>25 \mathrm{~m}$ from each scan point were not included in the range image. Range images were constructed by rasterizing the data with 1,600 pixel resolution in the 360 degree horizontal range, using the closest contact in each pixel. Visual inspection of matching images provided an immediate and intuitive basis for understanding the differences in quantitative metrics calculated from the data.

As a further aid to visual interpretation, we extracted matching slices through the point clouds of the combined scan data for each scanner at each site. These included the following: a vertical slice $2 \mathrm{~m}$ wide that passed through the plot center, which was useful for understanding horizontal and vertical penetration and subsequent reconstruction of threedimensional stand structure; a horizontal slice $0.1 \mathrm{~m}$ thick, centered at breast height $(1.3 \mathrm{~m})$ above ground surface at the plot center, which was useful for understanding differences in reconstructed forest inventory attributes; and a horizontal slice $2 \mathrm{~m}$ thick, centered at mid-canopy height $(10 \mathrm{~m})$ above ground surface at the plot center, which was useful for understanding likely differences in reconstructions of crown size, shape, and position.

\section{Scanner Penetration}

For each scanner, we quantified penetration through the canopy horizontally and vertically. We used the cumulative fraction of contacts within a given distance from each scanner position (including only those contacts originating from that position, and excluding probes that did not yield a return) as a measure of penetration. Penetration was quantified in terms of horizontal and vertical distances because we hypothesized that the anisotropic structure of the forest canopy might lead to differences in scanner performance in each dimension.

\section{Stem Mapping}

To ensure an objective comparison between the scanners and the modes of measurement, we implemented an identical algorithm to extract stem positions and stem diameters. The algorithm is based on the tendency for stems to completely block ground-level returns that are behind them from the vantage point of a single scan position. By contrast, low-lying twigs and foliage only partially occlude the ground behind them. Moreover, as branches are normally not connected to the ground, this will lead to measured ground points farther away from the scanner than the branch. Thus, a narrow void within a single scan within which no ground-level returns occur is likely to contain a tree stem at the apex of the void pointing toward the scan position.
Once a void is detected, indicating a possible stem location, the algorithm includes two further steps. First, the points above the ground near the apex of the void are clustered based on their distance. Clusters with enough points are used as potential stem positions. Starting with these potential stem positions, a second step is performed to extract a diameter, if possible. For the stem diameter estimation, not only one scan from one position is used, but also all available scans merged to one point cloud. A subset of points around each potential stem position is selected. These points are grouped to layered grids. Only points that are in grid cells which have corresponding occupied cells in at least four different layers are selected, indicating a vertically-oriented object. With this layering, horizontal structures are removed, as they occupy only one or two layers locally. For example, such objects could include a whorl of horizontally-oriented branches surrounding a vertically-oriented stem. Next, a distance-based clustering is applied with an ellipsoidal distance function. This is done because stems have higher vertical spread than horizontal spread; the ellipsoidal distance function leads preferentially to the vertical rather than horizontal expansion of the cluster. Finally, for each cluster, a circle is fitted and the best fitting circle is used as a stem diameter.

\section{Canopy Attributes}

For each scanner position, we calculated canopy gap fraction as the simple proportion of probes that failed to return a contact within each of 16 equally spaced inclination angle classes. The resulting canopy gap fractions were then used as input into the leaf area inversion model described by Norman and Campbell (1989) using the same 16 leaf inclination angle classes for estimation. Although more sophisticated approaches are available with TLS data, as with hemispherical photography (e.g., estimating canopy gap fraction in multiple azimuthal regions (cf. Lang and Yuequin, 1986); estimation of leaf area in voxelized subspaces (Henning and Radtke, 2006a; Hosoi and Omasa, 2009)), we focused on this relatively simple procedure as one that would highlight any differences due to scanner attributes without miring the analysis in algorithmic complexity. The procedure yielded estimates of effective plant area index $\left(\mathrm{PAI}_{\text {eff }}\right.$; cf. Chen et al., 1997) and mean tip angle (MTA) for each scanner location, for each scanner. These estimates were tested for statistically significant differences using mixed-effects ANOVA, with scanner (Leica, Riegl last return, or Riegl first return) and scanner by site interaction as fixed effects, and with site and position within site as random effects. These models were compared to null models that only included the random effects. Models were fit by using restricted maximum likelihood, even though ANOVA statistics estimated using this method are approximate; had any tests been ambiguous, they would have been repeated using bootstrapped likelihood ratio statistics. Statistical analysis was conducted using the NLME library (Pinheiro et al., 2009) in the R statistical package (R Development Core Team, 2009).

\section{Results}

\section{Visualization}

Range images for the two scanners at the plot centers of both sites are shown in Plate 1. Some general attributes of the scans can be discerned from these images, and are consistent across the range images from all scan points (not shown). First, as might be anticipated, the finer beam of the Leica scanner results in a greater level of apparent detail, even though the angular resolution of the scan is lower. For example, the Leica is better able to resolve both dead and foliated lower branches of nearby trees than the Riegl in either mode. Such features appear thicker and "padded" in the Riegl scans, in 


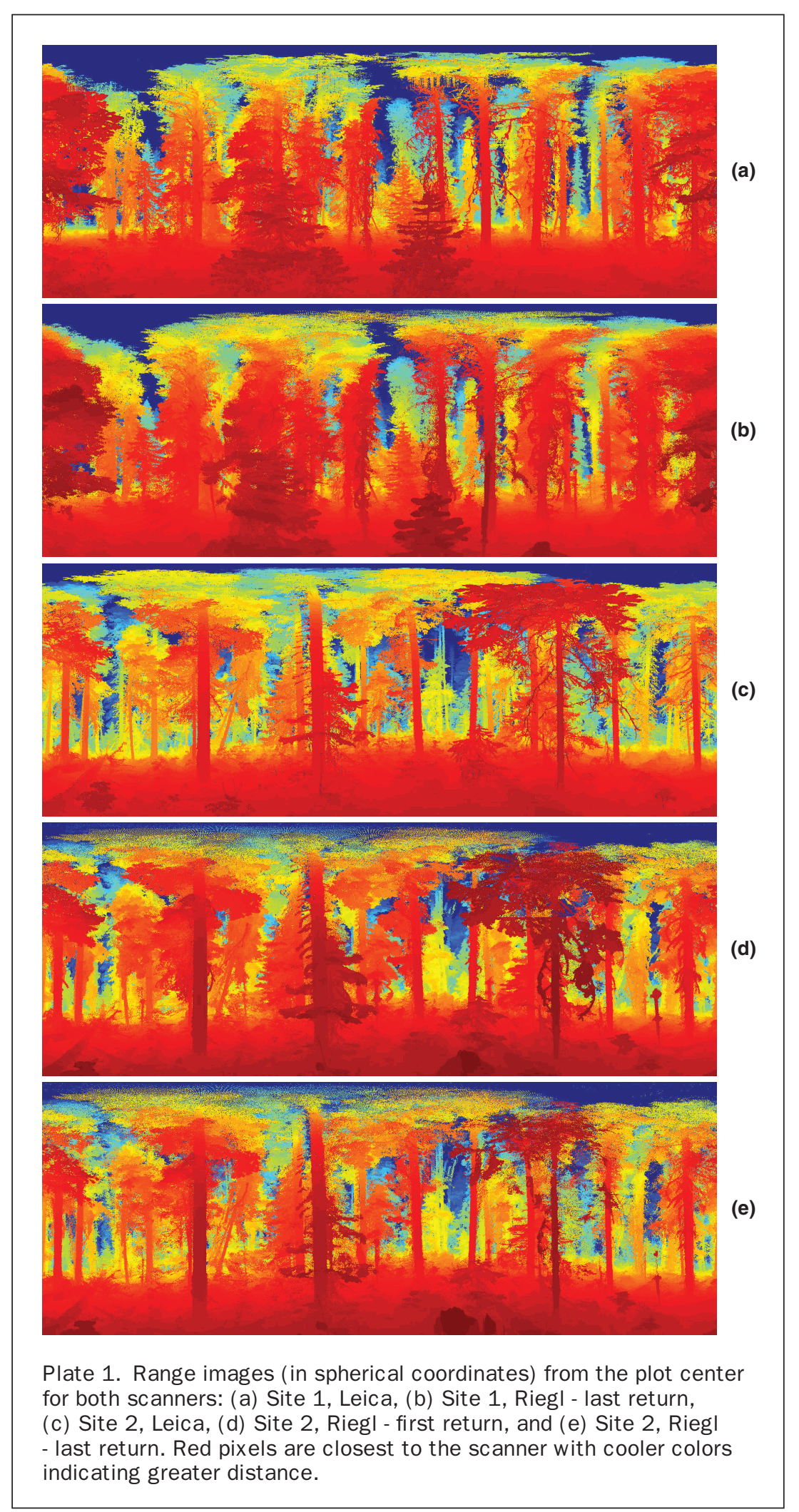

comparison with the Leica. Visually, the range maps from the Riegl used in last-return mode are more similar to those of the Leica than are those from first-return scans, but these differences are qualitative and hence difficult to quantify and are open to subjective interpretation. It is also apparent that the Riegl first-return and last-return scans can differ substantially in their rendering of semi-transparent nearby objects, such as foliated branches and small trees, as well as fine-textured objects such as dead branches. Such objects are much more opaque and heavily padded in first-return scans, but can also be almost transparent in last-return scans. The range images also show the difference in intensity of scan patterns near 
the zenith: the Leica provides a very high intensity pattern (a consistent separation in spherical coordinates $\theta$ and $\phi$, implying adjacent probes are actually closer together as elevation increases toward the zenith), whereas the Riegl maintains a more uniform separation (which graphs as a more dispersed pattern in spherical coordinates).

The qualitative characteristics seen in the range images carry forward into attributes of the point clouds. Figure 1 shows vertical slices through the point clouds. In these images, the finer-beamed Leica scanner is able to resolve finer detail than the Riegl, but the Riegl is better suited for describing the tops of all trees, especially those in Site 2, when it was used in last-return mode. However, the images share many similarities. In general, the same trees are recognizable with the same shapes and in the same positions. This implies that competent, flexible algorithms should be able to discriminate and measure gross structural attributes (e.g., number, size, and spatial distribution of tree crowns) in similar ways using either scanner.

Figures 2 and 3 show horizontal slices through the point clouds, centered at breast height above the plot center. Here, the differences are more striking. The fine-beamed Leica scans clearly show individual tree trunks, with many stems represented as hollow circles surrounded by a narrow ring of returns. This is also the case for trees that have branches and foliage surrounding the stem (see, e.g., Figure 3).

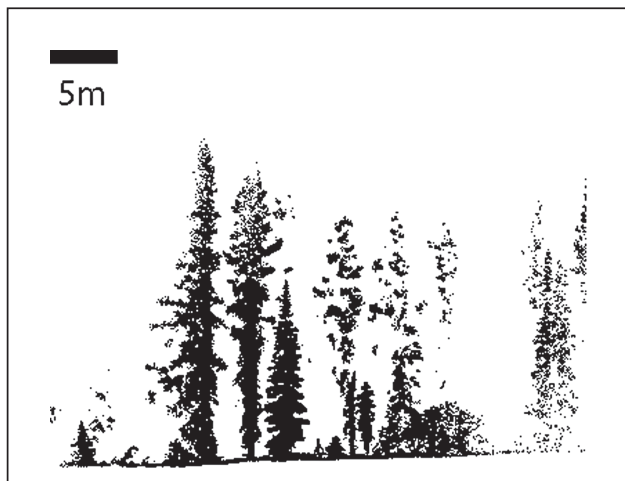

(a)

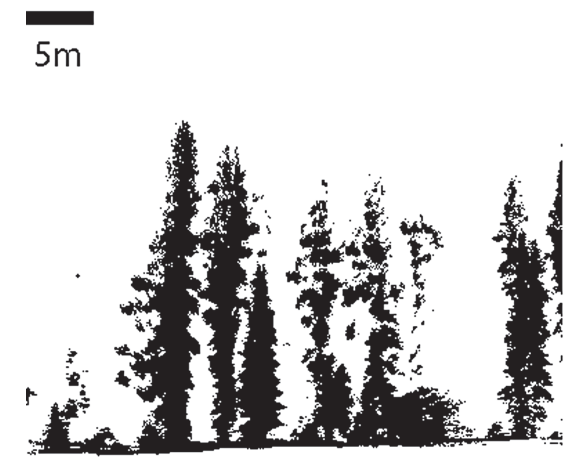

(b)

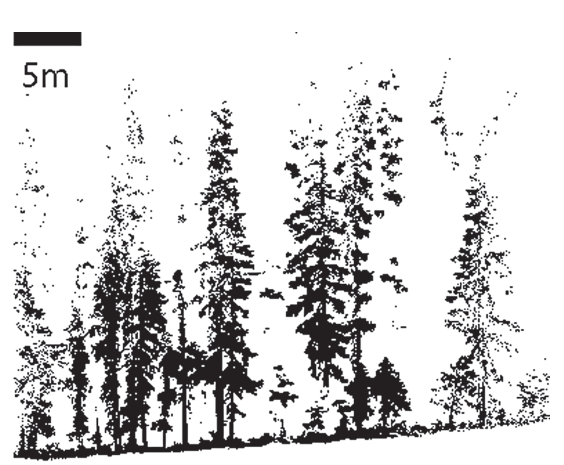

(c)

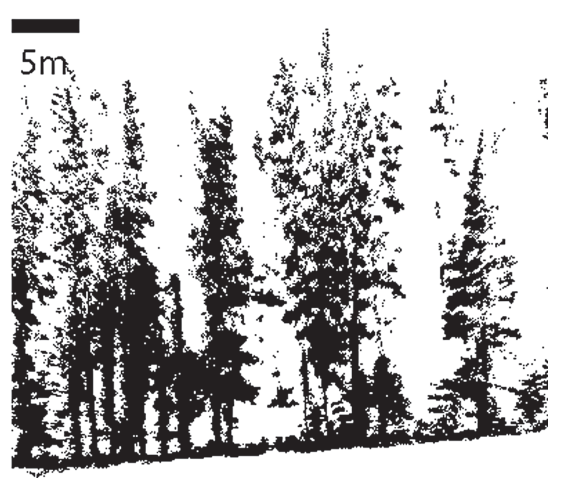

(d)

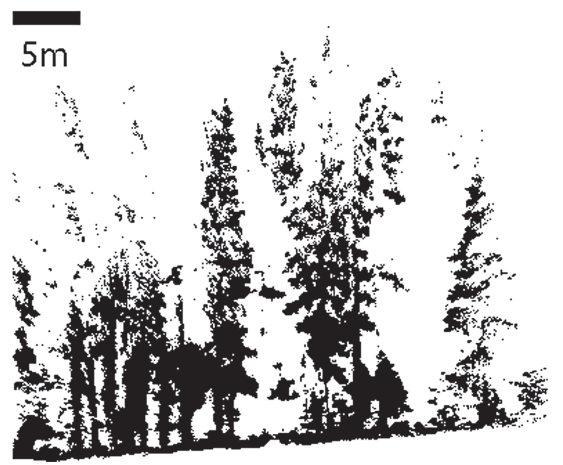

(e)

Figure 1. Vertical slices through the point cloud, $2 \mathrm{~m}$ thick, passing through the plot center: (a) Site 1, Leica, (b) Site 1, Riegl - last return, (c) Site 2, Leica, (d) Site 2, RiegI - last return, and (e) Site 2, Riegl - first return. In the Leica scans a target tripod approximately $1.8 \mathrm{~m}$ tall can just barely be seen at the plot center (at ground level near the center of the image). 


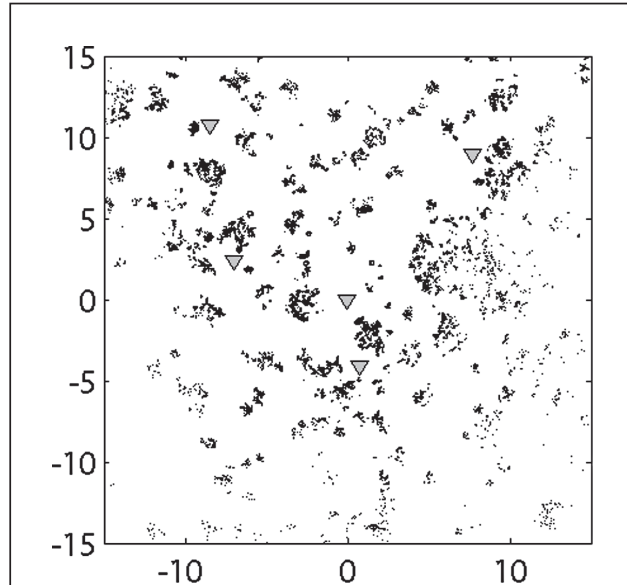

(a)

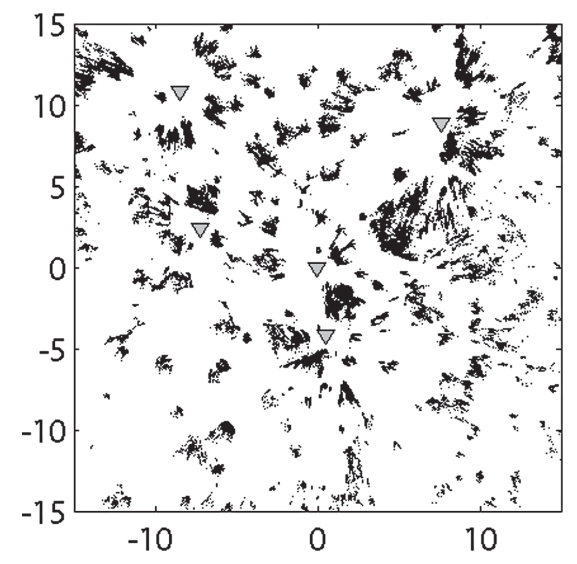

(b)

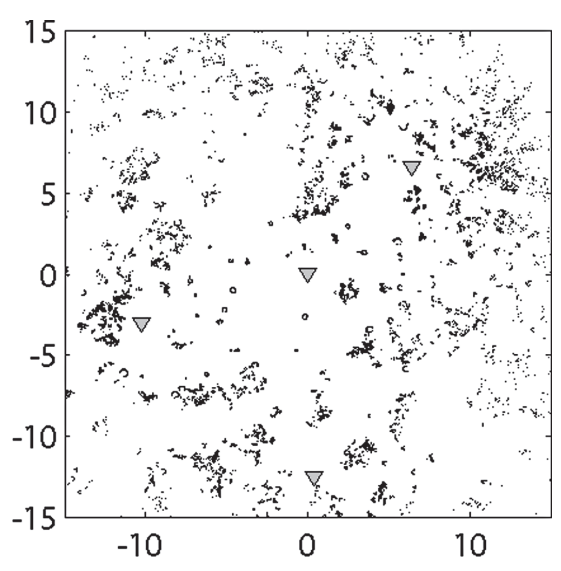

(c)

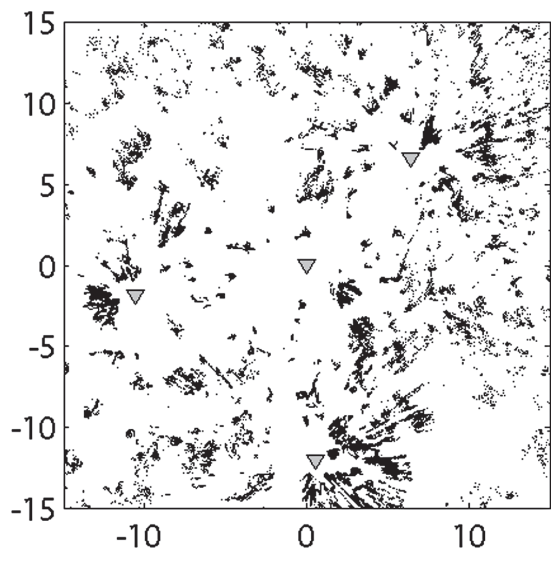

(d)

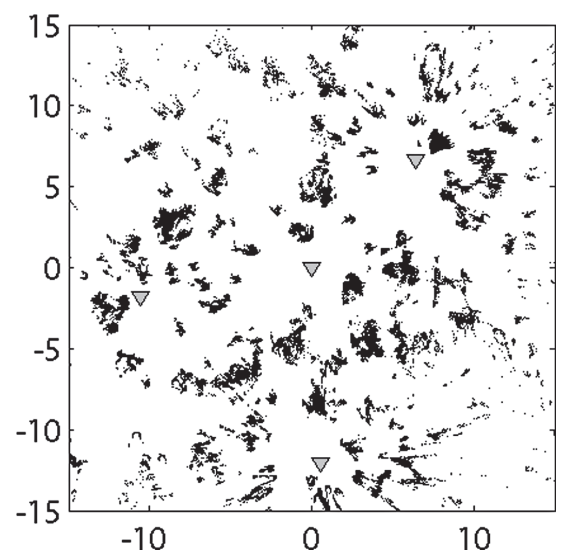

(e)

Figure 2. Horizontal slices through the point cloud, $0.1 \mathrm{~m}$ thick, centered $1.3 \mathrm{~m}$ above ground surface at the plot center; axes show coordinates in meters, with tripod locations as shaded triangles: (a) Site 1, Leica, (b) Site 1, Riegl - last return, (c) Site 2, Leica, (d) Site 2, Riegl - last return, and (e) Site 2, Riegl first return.

Corresponding tree stems in the coarser-beamed Riegl scans remain obvious, although they are not as simply rendered. Where the scan interacts with foliage and branches at breast height, there can be a characteristic smearing of these structures radially away from the scanner. These artifacts are known as intermediate points, and result from multiple reflections within a single impulse. If the reflecting surfaces in one laser impulse have smaller distance differences than the 


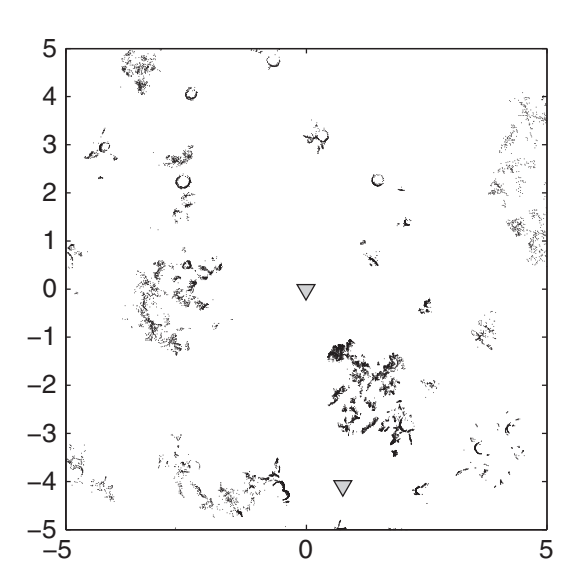

(a)

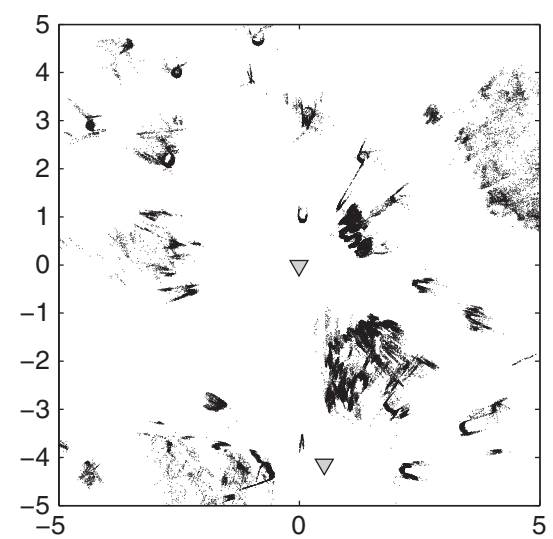

(b)

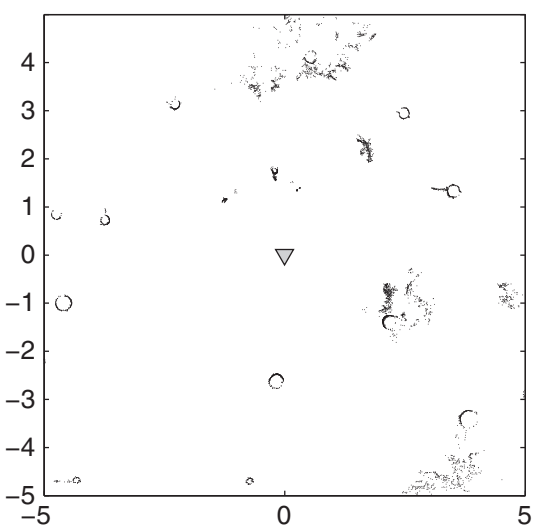

(c)

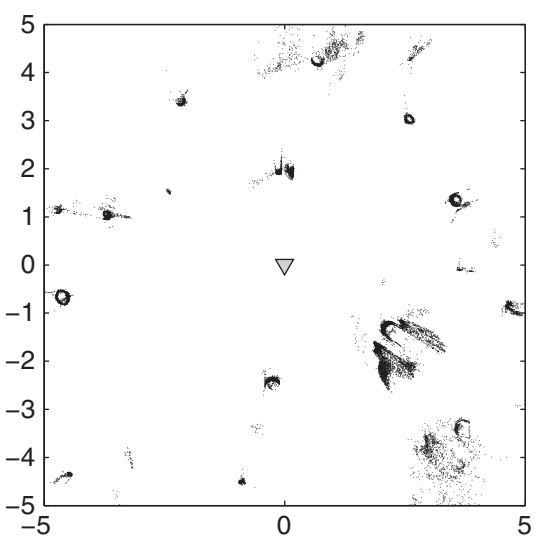

(d)

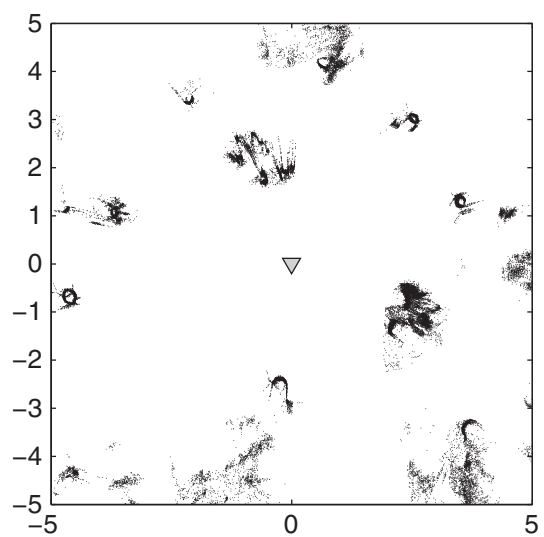

(e)

Figure 3. Close-up of the horizontal slice at $1.3 \mathrm{~m}$ above plot center, showing the differences in rendering of individual tree stems within the point cloud, with tripod locations as shaded triangles: (a) Site 1, Leica, (b) Site 1, Riegl - last return, (c) Site 2, Leica, (d) Site 2, Riegl - last return, and (e) Site 2, Riegl first return.

length of the laser impulse, it will not be possible to separate them and an average distance will be measured. This could lead to points appearing in the point cloud that fall between the positions of the physical objects in the scan. These features imply that algorithms for identifying and mapping individual tree stems might work differently with data from the two scanners, and careful cross-calibration might be needed in an inventory context.

Finally, slices through the point clouds at mid-canopy position (Figure 4) show reasonable qualitative agreement between scanners. The Leica continues to show a greater degree of fine detail, such as the characteristic star-shaped 


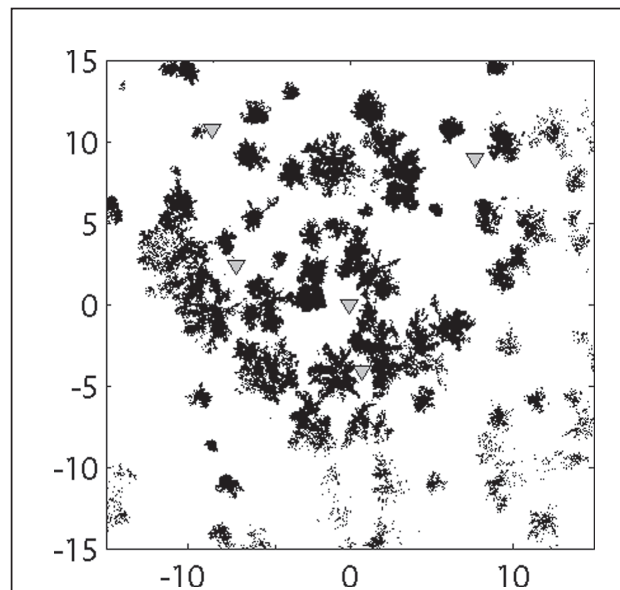

(a)

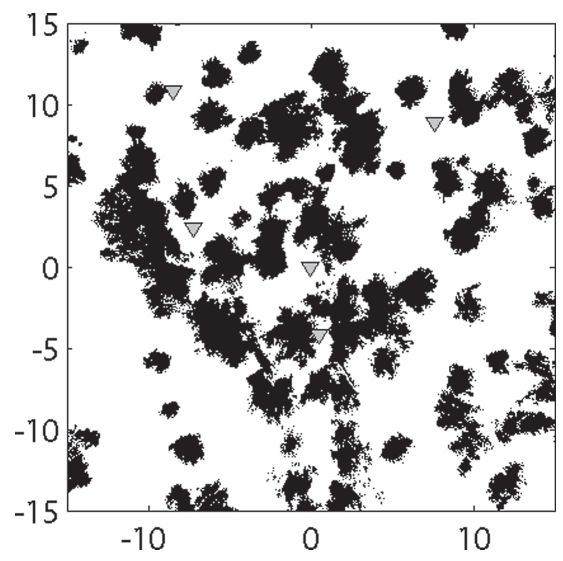

(b)

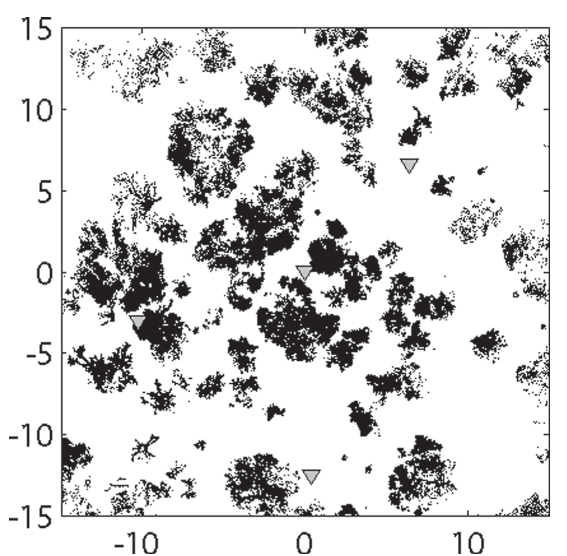

(c)

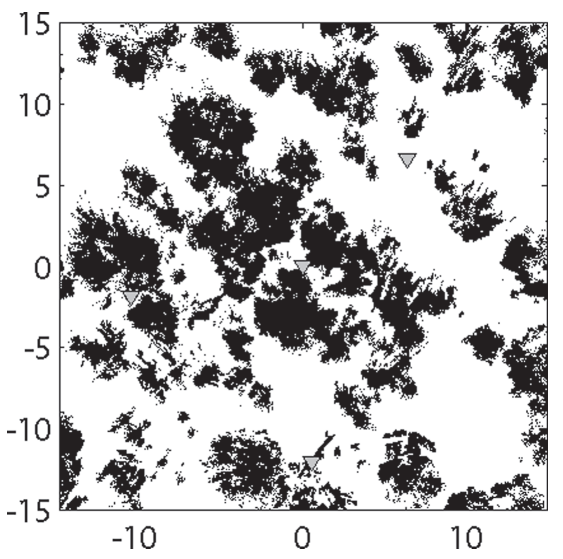

(d)

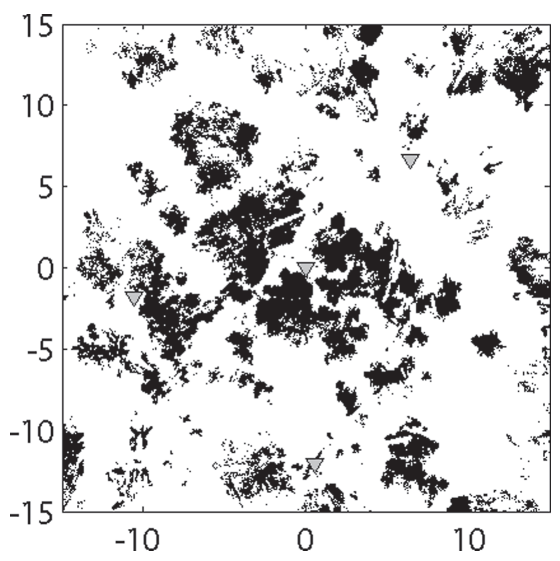

(e)

Figure 4. Horizontal slices through the point cloud, $2 \mathrm{~m}$ thick, centered $10 \mathrm{~m}$ above ground surface at the plot center; axes show coordinates in meters, with tripod locations as shaded triangles: (a) Site 1, Leica, (b) Site 1, Riegl - last return, (c) Site 2, Leica, (d) Site 2, Riegl - last return, and (e) Site 2, Riegl first return.

branching pattern of some lodgepole pine crowns, while the Riegl does not show such detail as readily. The positions and sizes of crowns recorded by the two scanners are generally consistent, although the Riegl shows the same slight padding of branches and other fine features as in other visualizations, leading to a slight loss of negative space between crowns. Otherwise, for gross structural characterization of the canopy, the two systems appear to give similar results. 


\section{Scanner Penetration}

For horizontal penetration, both the Leica and the Riegl used in last-return mode showed consistent differences (Figure 5). For example, at Site 1 the median horizontal distance to return for the Leica was $2.81 \mathrm{~m}$, whereas for the Riegl it was $4.33 \mathrm{~m}$. At Site 2, the corresponding distances were $3.55 \mathrm{~m}$ and $8.92 \mathrm{~m}$, respectively. However, the Riegl used in firstreturn mode had similar penetration to the Leica, with a median horizontal distance to return of $3.94 \mathrm{~m}$.

Vertical penetration showed a different pattern than horizontal penetration (Figure 5). The Leica and the Riegl in last-return mode had similar vertical penetration $(3.02 \mathrm{~m}$ as opposed to $3.15 \mathrm{~m}$ median vertical distance to return at Site 1, and $4.15 \mathrm{~m}$ as opposed to $4.03 \mathrm{~m}$ at Site 2). However, the Riegl in first-return mode showed much less vertical penetration (2.34 $\mathrm{m}$ at Site 2).

\section{Stem Mapping}

The results of stem position detection in both stands are given in Table 3. Both site conditions and scanner attributes appear to have impacted the number of detected stems, including the propensity for false positives and false negatives. At Site 1, more potential tree positions were found with the Leica scanner, and also more trees could be matched with manually extracted stem positions using the Leica. At Site 2, the Leica again performed better than the Riegl in first-return mode, but the Riegl in last-return mode performed best. Site 2 had more dead and living branches occluding the stems, leading to false positives. The broader beam of the Riegl scanner may have contributed to false positives due to the intermediate points between the real stems. However, the false positives also included the poles to hold the reflectors or registration targets.

Using the potential stem positions as a starting point, stem diameters for Site 2 were extracted. The results are summarized in Figure 6. There was a tendency for both Riegl scanner modes to slightly underestimate stem diameters, but the Leica showed greater variability. The Riegl in last-return mode showed the best performance, as judged by mean absolute deviation (MAD). However, none of the scanners or modes provided sufficiently reliable diameter measurements using the algorithm employed here to substitute for traditional measurements using a tape or calipers.

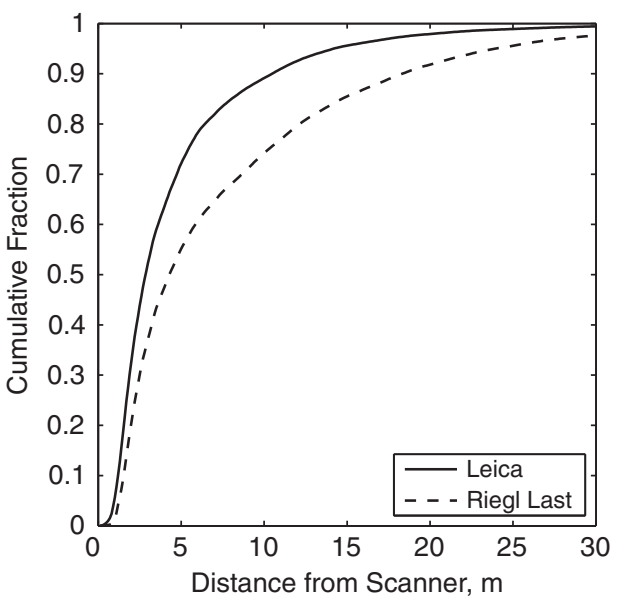

(a)

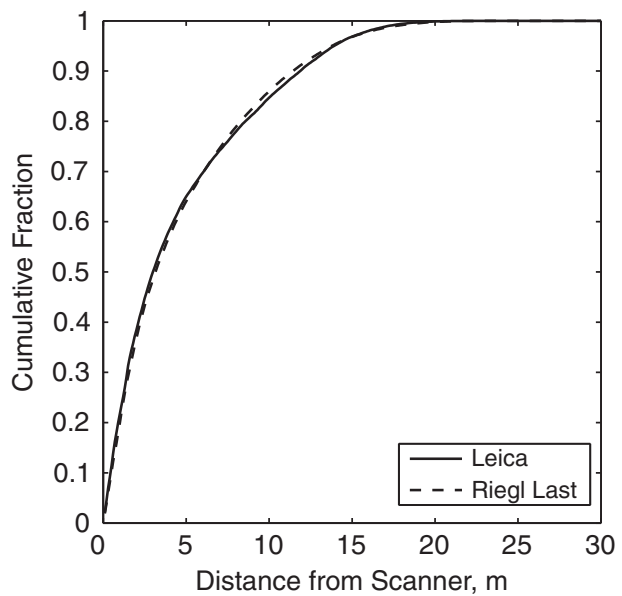

(b)

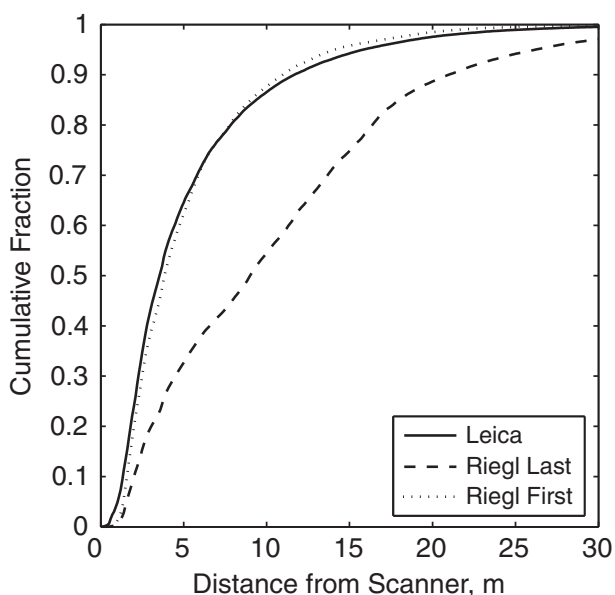

(c)

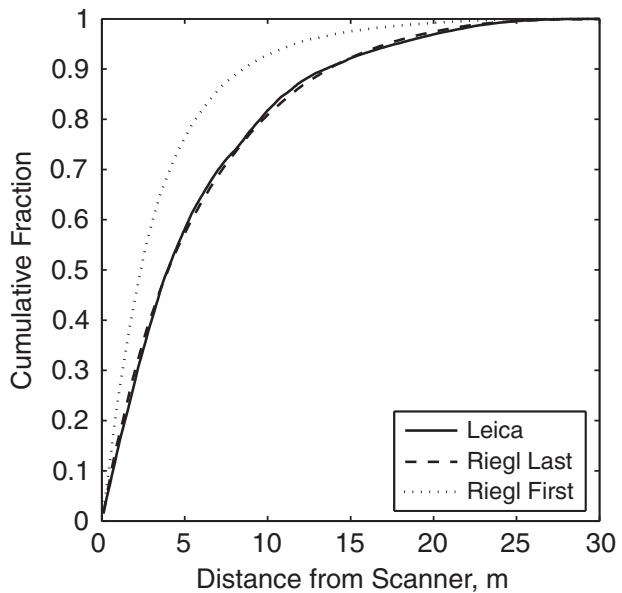

(d)

Figure 5. Cumulative horizontal and vertical penetration of returns from both scanners at both sites, excluding non-contact returns: (a) Site 1 - horizontal, (b) Site 1 - vertical, (c) Site 2 - horizontal, and (d) Site 2 - vertical. 
Table 3. Results of Stem Mapping

\begin{tabular}{lccc}
\hline Site 1: 71 manually extracted trees & & \\
\hline Scanner & Potential Positions & Correct Matches & Trees Not Found \\
Leica & 80 & 29 & 42 \\
Riegl (first return) & 68 & 21 & 50 \\
\hline Site 2: 45 manually extracted trees & & \\
\hline Scanner & Potential Positions & Correct Matches & Trees Not Found \\
Leica & 73 & 25 & 20 \\
Riegl (first return) & 96 & 29 & 16 \\
Riegl (last return) & 72 & 30 & 15 \\
\hline
\end{tabular}

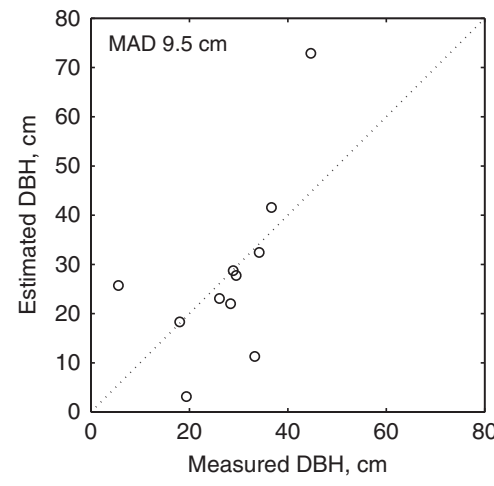

(a)

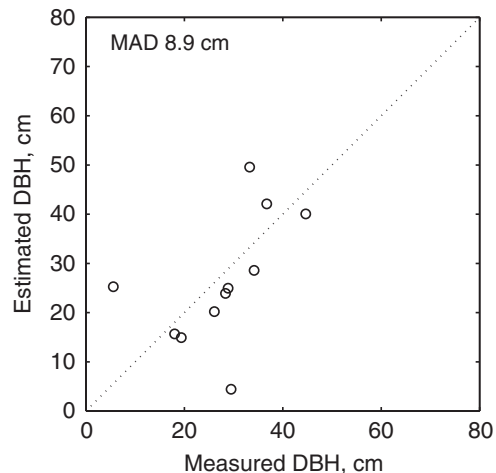

(b)

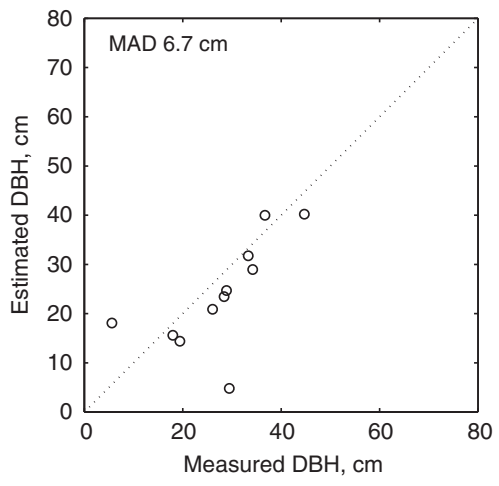

(c)

Figure 6. Comparison of diameter extraction at Site 2 for trees that were detected by all three scanner/ mode combinations: (a) Leica, (b) Riegl - first return, and (c) Riegl - last return.

\section{Canopy Attributes}

Gap fraction as a function of zenith angle is shown for the two scanners in Figure 7. At Site 1, the Leica had a higher mean gap fraction for angles near the zenith than the Riegl used in last-return mode, but a lower mean gap fraction for angles greater than 60 degrees from zenith (i.e., less than approximately 30 degrees from horizontal). At Site 2, the pattern was similar. Here, the Leica had a higher mean gap fraction than the Riegl used in either mode for angles less than 50 degrees from zenith, but a lower gap fraction for angles more than 50 degrees from zenith.

The impact of different estimates of gap fraction on effective plant area index and mean tip angle are shown in Table 4. The Leica provided consistently higher estimates of plant area index than the Riegl. These differences were highly significant (likelihood ratio chi-square 21.73, p <0.0001). Differences in mean tip angle, although marginally significant from a statistical perspective (likelihood ratio chi-square 6.75, $\mathrm{p}=0.034$ ), are so small (only a fraction of a degree between scanners and sites) as to be practically inconsequential. Both the binning of zenith angles during analysis, and the approximate nature of the statistical hypothesis test, can be considered as arguments against any attempt to interpret such trivial differences in mean tip angle.

\section{Discussion}

Although both of the scanners employed in our study are relatively high-resolution scanners, capable of acquiring point clouds with millions of points in a single hemispheric scan, the differences upon visual inspection of range maps as well as scatter plots of slices through point clouds are striking and informative. The scanners differ in numerous design attributes, including laser wavelength and power, beam divergence, and data pre-processing. Because the latter occurs within the scanner unit before export and often is proprietary information, it is difficult to evaluate its full impact. However, at least some of most obvious visual differences are attributable to beam diameter, which depends on diameter of the beam exiting the instrument and on beam divergence. The comparison shows that a small beam diameter leads to better penetration through low branches and understory vegetation (Figure 3) potentially giving small beam diameter scanners a greater potential for deriving stem properties. Significant divergence in beam diameter exists between scanners employed in forestry applications, and the presented results show that beam diameter is an important parameter to consider when choosing an instrument and interpreting derived variables. Even though there is significant divergence in beam diameter between the two compared scanners (Table 2), both scanners have narrower beams at operational distances of 10 to $20 \mathrm{~m}$ than for example the ECHIDNA instrument used by Jupp et al. (2005) and Strahler et al. (2008).

The ability of a scanner to penetrate a forest stand will be a critical determinant of multiple aspects of performance. Greater penetration should, in principle, allow recovery of stand structure from fewer scan positions or from positions placed farther apart. All other things being equal, a scanner 


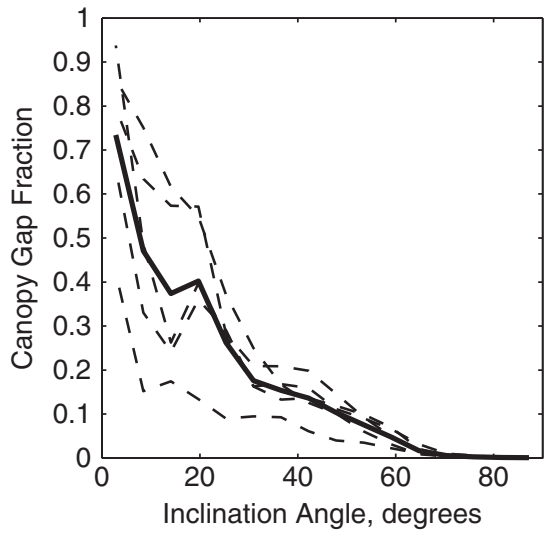

(a)

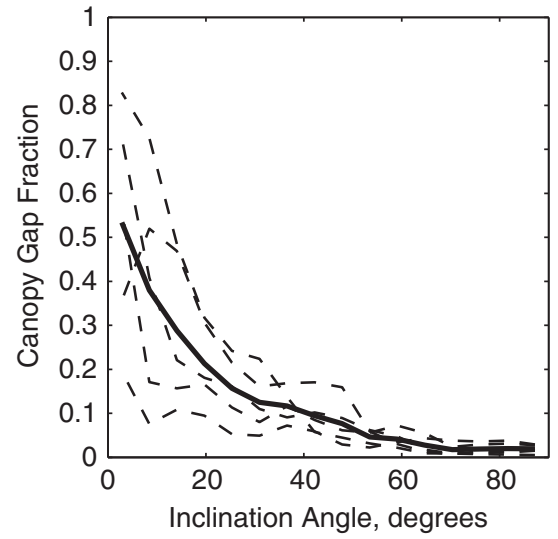

(b)

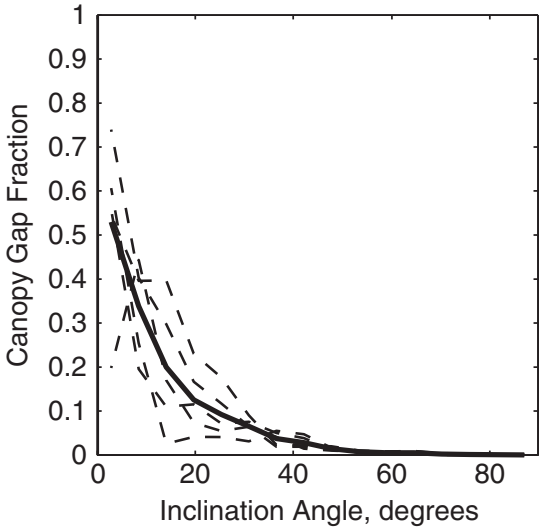

(c)

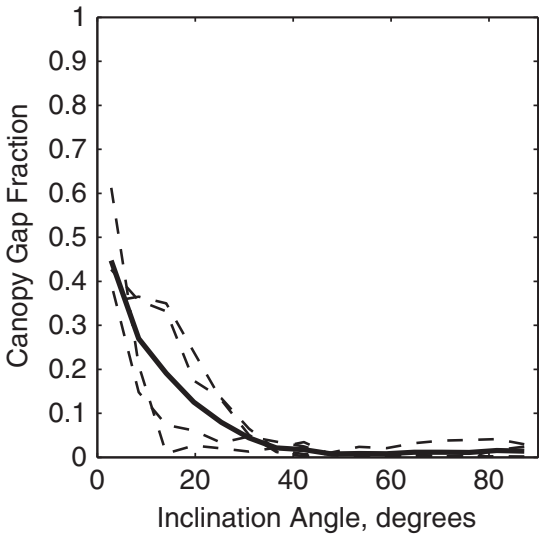

(d)

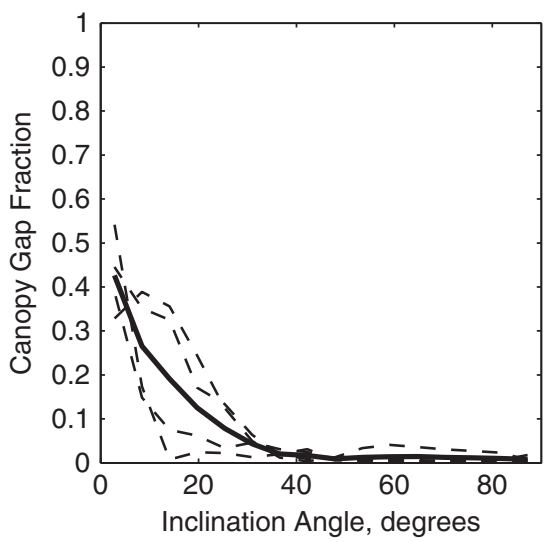

(e)

Figure 7. Canopy gap fraction as a function of angle of inclination at each scan position (dashed lines) and average overall positions (solid line) for both scanners at both sites: (a) Site 1, Leica, (b) Site 1, Riegl - last return, (c) Site 2, Leica, (d) Site 2, Riegl - last return, and (e) Site 2, Riegl - first return.

with greater penetration should be able to map and identify individual trees at a greater distance from the scan position. Greater penetration should also allow better reconstruction of the attributes of upper canopies, although if such penetration occurs because returns are not being provided for lower canopy elements, there may be tradeoffs in resolving different canopy layers. We speculate that the observed differences in patterns between horizontal and vertical penetration (Figure 5) are caused by differences in the geometric configuration of canopy elements and their interaction with scanner properties. For vertical penetration, the horizontal sprays of conifer foliage and fine branches, which are relatively efficient for capturing sunlight, may also be relatively opaque to the Riegl when used in first-return mode, but can be penetrated by the 
Table 4. Estimates of Effective Plant Area Index (PAI eff and Mean Tip ANGLE (MTA) FOR EACH SCANNER AND SITE

\begin{tabular}{|c|c|c|c|c|c|}
\hline \multirow[t]{2}{*}{ Scanner } & & \multicolumn{2}{|c|}{ Site 1} & \multicolumn{2}{|c|}{ Site 2} \\
\hline & & Mean & Std. Dev. & Mean & Std. Dev. \\
\hline \multirow[t]{2}{*}{ Leica } & $\mathrm{PAI}_{\text {eff }}$ & 2.08 & 0.09 & 2.28 & 0.11 \\
\hline & MTA & 23.5 & 2.6 & 25.1 & 0.3 \\
\hline \multirow[t]{2}{*}{ Riegl (Last Return) } & $\mathrm{PAI}_{\text {eff }}$ & 1.31 & 0.15 & 1.68 & 0.24 \\
\hline & MTA & 23.4 & 0.4 & 25.6 & 0.2 \\
\hline \multirow[t]{2}{*}{ Riegl (First Return) } & $\mathrm{PAI}_{\text {eff }}$ & & & 1.74 & 0.43 \\
\hline & MTA & & & 25.6 & 0.1 \\
\hline
\end{tabular}

fine beam of the Leica or, with reasonable frequency, by a sufficient signal to allow a more distant detection when the Riegl is used in last-return mode.

Given the employed algorithms, which were developed specifically for the comparison task, neither of the scanners performed particularly well in the stem mapping and diameter extraction tasks. We note that the algorithm was not specifically optimized for any of the scanner setups, as doing so would have compromised the comparison. The stem mapping and diameter extraction results are consequently not an indication of the potential for TLS for these operations and significantly better performance has been shown in numerous studies (e.g., Brolly and Kiraly, 2009; Henning and Radtke, 2006b; van Leeuwen et al., 2011; but see Thies and Spiecker (2004) for a study with similarly low detection rates). Our study does not include a formal comparison between algorithms, so we do not advocate for or against our algorithm here. However, the differences in performance between scanners suggest that point cloud attributes that depend in turn on scanner characteristics do matter for stem mapping and related inventory tasks. Maas et al. (2008) also suggested that beam divergence might impact the accuracy of tree diameter recovery. Hence, scanner-specific algorithm optimization is likely to be necessary as long as algorithms are not specifically designed to account for specific scanner properties and their interactions with forest canopies. The poor stem mapping and diameter extraction performance can partly be attributed to lack of scanner optimization, but also to the selected stand conditions with a high degree of low branching (Figures 1 and 2), a condition that has been underrepresented in field tests of TLS and inventory attributes.

Differences between effective PAI estimates for the two scanners were significantly different, and were larger than the estimated differences between the two sites, thus highlighting the need to account for scanner specifications in interpretation of results. The similarity in estimated plant area index between the two sites was unexpected given the striking differences in soil resources. However, given that the figures reported are effective PAI (Chen et al., 1997), actual differences may have been masked by differences in shoot-level clumping between pine (which dominated the canopy of Site 1, which had poorer soils) and spruce and fir (which are dominant at Site 2, which had richer soils). The greater clumping of spruce and fir needles should have led to a more substantial underestimate of LAI and PAI at that site.

A potential advantage of TLS over hemispherical photography is that in principle it is unnecessary to set threshold values to calculate gap fraction, as must be done for photographs (Jonckheere et al., 2005). Thus, gap fraction estimates and derived quantities such as PAI should be more consistent between observers, and should depend less on sky conditions. However, the results obtained in our study suggest that scanner attributes, including beam size and maximum range, may be important for interpreting gap fractions and values calculated from them.
It had been previously hypothesized, but not demonstrated in a controlled study, that details of the scanner might be important for derived forest attributes (Clawges et al., 2007; Zheng and Moskal, 2009). Conversely, fine-beam TLS systems are capable of imaging with increasingly high resolution and spatial accuracy (Dassot et al., 2011). Thus, it might be tempting to believe that while details of the point clouds from different scanners might vary, the results in terms of derived characteristics would be quite small, especially in comparison to the substantial differences sometimes observed between terrestrial and airborne scanning (e.g., Chasmer et al., 2006; Hilker et al., 2010 and 2012). Moreover, the emerging uses of this technology for ecological investigations (see, e.g., Vierling et al., 2008; Dassot et al., 2011; van Leeuwen et al., 2011) and declines in scanner cost may encourage new users to explore TLS who are not dedicated lidar researchers and who might, therefore, not find the consequences of differing TLS configurations intuitive. Our results should serve as a caution against naive comparison of results derived from data from different TLS scanners.

In conclusion, we share the optimism of several authors (e.g., Henning and Radtke, 2006a; Strahler et al., 2008, Dassot et al., 2011; van Leeuwen et al., 2011) that terrestrial laser scanning will be an important tool for describing forest attributes in the future, but highlight that scanner attributes such as beam size, wave length, and maximum range may have strong implication for the derived results. In this, we echo the conclusions of Chasmer et al. (2006) who emphasize the need to understand how specific laser scanners (whether airborne or terrestrial) interact with vegetated canopies in order to improve the reliability and consistency of scannerderived forest attributes.

\section{Acknowledgments}

We thank the Bulkley Valley Research Centre for use of their research sites, for the field assistance of Beth Henderson and Tlell Glover, and for general logistical help with the study. This project was supported by the BC Ministry of Forests and Range Forest Science Program.

\section{References}

Aschoff, T., and H. Spiecker, 2004. Algorithms for the automatic detection of trees in laser scanner data, Proceedings of the ISPRS Working Group VIII/2, "Laser-Scanners for Forest and Landscape Assessment," Freiburg, Germany, 03-06 October, International Archives of Photogrammetry, Remote Sensing and Spatial Information Sciences, XXXVI, Part 8/W2, pp. 71-75.

Aschoff, T., M. Thies, and H. Spiecker, 2004. Describing forest stands using terrestrial laser-Scanning, Proceedings of the $X X^{\text {th }}$ ISPRS Congress "Geo-Imagery Bridging Continents," Istanbul, Turkey, 12-23 July, International Archives of Photogrammetry, Remote Sensing and Spatial Information Sciences. XXXV: Part B5, pp. 237-241.

Banner, A., W. MacKenzie, S. Haeussler, S. Thomson, J. Pojar, and R. Trowbridge, 1993. A Field Guide to Site Identification and Interpretation for the Prince Rupert Forest Region B.C., Land Management Handbook 26, Ministry of Forests Victoria, British Columbia, 503 p.

Brolly, G., and G. Kiraly, 2009. Algorithms for stem mapping by means of terrestrial laser scanning, Acta Silvatica \& Lignaria Hungarica, 5:119-130.

Chasmer, L., C. Hopkinson, and P. Treitz, 2006. Investigating laser pulse penetration through a conifer canopy by integrating airborne and terrestrial lidar, Canadian Journal of Remote Sensing, 32(2):116-125.

Chen, J.M., P.M. Rich, S.T. Gower., J.M. Norman, and S. Plummer, 1997. Leaf area index of boreal forests: Theory, techniques and measurements, Journal of Geophysical Research, 102(D24):29, 429-29, 443. 
Clawges, R., L. Vierling, M. Calhoon, and M. Toomey, 2007. Use of a ground-based scanning lidar for estimation of biophysical properties of western larch (Larix occidentalis), International Journal of Remote Sensing, 28(19):4331-4344.

Dassot, M., T. Constant, and M. Fournier, 2011. The use of terrestrial LiDAR technology in forest science: Application fields, benefits and challenges, Annals of Forest Science 68(5):959-974.

Eitel, J.U.H., L.A. Vierling, and D.S. Long, 2010. Simultaneous measurement of plant structure and chlorophyll content in broadleaf saplings with a terrestrial laser scanner, Remote Sensing of Environment, 114(10):2229-2237.

Englund, S.R., J.J. O'Brien, and D.B. Clark, 2000. Evaluation of digital and film hemispherical photography and spherical densiometry for measuring forest light environments, Canadian Journal of Forest Research, 30(12):1999-2005.

Hale, S., and C. Edwards, 2002. Comparison of film and digital hemispherical photography across a wide range of canopy densities, Agricultural and Forest Meteorology, 112(1):51-56.

Henning, J.G., and P.J. Radtke, 2006a. Ground-based laser imaging for assessing three-dimensional forest canopy structure, Photogrammetric Engineering \& Remote Sensing, 72(12):1349-1358.

Henning, J.G., and P.J. Radtke, 2006b. Detailed stem measurements of standing trees from ground-based scanning lidar, Forest Science, 52(1):67-80.

Hilker, T., N.C. Coops, G.J. Newnham, M. van Leeuwen, M.A. Wulder, J. Stewart, and D.S. Culvenor, 2012. Comparison of terrestrial and airborne LiDAR in describing stand structure of a thinned lodgepole pine forest, Journal of Forestry, 100(2):97-104.

Hilker, T., M. van Leeuwen, N.C. Coops, G.J. Newnham, D.L.B. Jupp, and D.S. Culvenor, 2010. Comparing canopy metrics derived from terrestrial and airborne laser scanning in a Douglas-fir dominated forest stand, Trees - Structure and Function, 24(5):819-832

Hopkinson, C., L. Chasmer, C. Young-Pow, and P. Treitz, 2004. Assessing forest metrics with a ground-based scanning lidar, Canadian Journal of Forest Research, 34(3):573-583.

Hosoi, F., and K. Omasa, 2007. Factors contributing to accuracy in the estimation of the woody canopy leaf area density profile using 3D portable lidar imaging, Journal of Experimental Botany, 58(12):3463-3473.

Hosoi, F., and K. Omasa, 2009. Detecting seasonal change of broadleaved woody canopy leaf area density profile using 3D portable LIDAR imaging, Functional Plant Biology, 36(11):998-1005.

Hosoi, F., K. Nakabayashi, and K. Omasa, 2011. 3-D modeling of tomato canopies using a high-resolution portable scanning lidar for extracting structural information, Sensors, 11(2):2166-2174.

Huang, P., and H. Pretzsch, 2010. Using terrestrial laser scanner for estimating leaf areas of individual trees in a conifer forest, Trees: Structure and Function, 24(4):609-619.

Jonckheere, I., S. Fleck, K. Nackaerts, B. Muys, P. Coppin, M. Weiss, and F. Baret, 2004. Review of methods for in situ leaf area index (LAI) determination: Part I. Theories, sensors and hemispherical photography, Agricultural and Forest Meteorology, 121(12):19-35.

Jonckheere, I., K. Nackaerts, B. Muys, and P. Coppin, 2005. Assessment of automatic gap fraction estimation of forests from digital hemispherical photography, Agricultural and Forest Meteorology, 132(1-2):96-114.

Jupp, D.L.B., D. Culvenor, J.L. Lovell, and G. Newnham, 2005. Evaluation and Validation of Canopy Laser Radar (LIDAR) Systems for Native and Plantation Forest Inventory, CSIRO Marine and Atmospheric Research Paper 20, CSIRO Marine and Atmospheric Research, Canberra, Australian Capital Territory (ACT), 150 p.

Lang, A.R.G., and X. Yuequin, 1986. Estimation of leaf area index from transmission of direct sunlight in a discontinuous canopies, Agricultural and Forest Meteorology, 37(3):229-243.

Maas, H.-G., A. Bienert, S. Scheller, and E. Keane, 2008. Automatic forest inventory parameter determination from terrestrial laser scanner data, International Journal of Remote Sensing, 29(5):1579-1593.

Lefsky, M., and M. McHale, 2008. Volume estimates of trees with complex architecture from terrestrial laser scanning, Journal of Applied Remote Sensing, 2:023521.
Meidinger, D., and R. Pojar (editors), 1991. Ecosystems of British Columbia, British Columbia Ministry of Forests Special Report Series 6, British Columbia Ministry of Forests, Victoria, British Columbia.

Moorthy, I., J.R. Miller, B. Hu, J. Chen, and Q. Li, 2008. Retrieving crown leaf area index from an individual tree using ground-based lidar data, Canadian Journal of Remote Sensing, 34(3):320-332.

Neumann, H., A. Yazdanbakhsh, and E. Mingolla, 2007. Seeing surfaces: The brain's vision of the world, Physics of Life Reviews, 4:189-222.

Norman, J.M., and G.S. Campbell, 1989. Canopy structure, Plant Physiological Ecology: Field Methods and Instrumentation (R.W. Pearcy, J. Ehleringer, H.A. Mooney, and P.W. Rundel, editors), Chapman and Hall, New York, pp. 301-325.

Pinheiro, J., D. Bates, S. DebRoy, D. Sarkar, and the R Core Team, 2009. nlme: Linear and Nonlinear Mixed Effects Models, R package, version 3.1-93.

R Development Core Team. 2009. R: A Language and Environment for Statistical Computing, ISBN 3-900051-07-0, R Foundation for Statistical Computing, Vienna, Austria.

Rossel, J.R., J. Llorens, R. Sanz, J. Arno, M. Ribes-Dasi, J. Masip, A. Escola, F. Camp, F. Solanelles, F. Gracia, E. Gil, L. Val, S. Planas, and J. Placin, 2009. Obtaining the three-dimensional structure of tree orchards from remote 2D terrestrial LIDAR scanning, Agricultural and Forest Meteorology, 149(9):1505-1515.

Simonse, M., T. Aschoff, H. Spiecker, and M. Thies, 2003. Automatic Determination of Forest Inventory Parameters Using Terrestrial Laser Scanning, Institute for Forest Growth, Freiburg, Germany, 7 p.

Strahler, A.H., D.L.B. Jupp, C.E. Woodcock, C.B. Schaaf, T. Yao, F. Zhao, X. Yang, J. Lovell, D. Culvenor, G. Newnham, W. Ni-Miester, and W. Boykin-Morris, 2008. Retrieval of forest structural parameters using a ground-based lidar instrument (Echidna ${ }^{\circledR}$ ), Canadian Journal of Remote Sensing, 34 (Supplement 2):S426-S440.

Thies, M., and H. Spiecker, 2004. Evaluation and future prospects of terrestrial laser-scanning for standardized forest inventories, Proceedings of the ISPRS Working Group VIII/2, "Laser-Scanners for Forest and Landscape Assessment," Freiburg, Germany, 03-06 October 2004, International Archives of Photogrammetry, Remote Sensing and Spatial Information Sciences, XXXVI, Part 8/W2, pp. 192-197.

Thies, M., N. Pfeifer, N.D. Winterhalder, and B. Gorte, 2004. 3D Reconstruction of stems for assessment of taper, sweep and lean based scanning of standing trees, Scandinavian Journal of Forest Research, 19(6):571-581.

Todd, J.T., 2004. The visual perception of 3D shape, TRENDS in Cognitive Sciences, 8(3):115-121.

Van der Zande, D., W. Hoet, I. Jonckheere, J. van Aardt, and P. Coppin, 2006. Influence of measurement set-up of ground-based LiDAR for derivation of tree structure, Agricultural and Forest Meteorology, 141(2-4):147-160.

Van der Zande, D., I. Jonckheere, J. Stuckens, W.W. Verstraeten, and P. Coppin, 2008. Sampling design of ground-based lidar measurements of forest canopy structure and its effect on shadowing, Canadian Journal of Remote Sensing, 34(6):526-538.

van Leeuwen, M., T. Hilker, N.C. Coops, G. Frazer, M.A. Wulder, G.J. Newnham, and D.S. Culvenor, 2011. Assessment of standing wood and fiber quality using ground and airborne laser scanning: A review, Forest Ecology and Management, 261(9):1467-1476.

Vierling, K.T., L.A. Vierling, W.A. Gould, S. Martinuzzi, and R.M. Clawges, 2008. Lidar: Shedding new light on habitat characterization and modeling, Frontiers in Ecology and the Environment, 6(2):90-99.

Watt, D., and N.M. Donoghue, 2005. Measuring forest structure with terrestrial laser scanning, International Journal of Remote Sensing, 26(7):1437-1446.

Zheng, G., and L.M. Moskal, 2009. Retrieving leaf area index (LAI) using remote sensing: Theories, methods and sensors, Sensors, 9(4):2719-2745 (doi:10.3390/s90402719).

(Received 14 October 2011; accepted 27 January 2012; final version 16 October 2012) 